UDC 53.047

LBC 30в6

\title{
NATURAL POLYMERS FOR 3D BIOPRINTING OF ORGANS
}

\author{
Galina A. Sroslova \\ Volgograd State University, Volgograd, Russian Federation \\ Yuliya A. Zimina \\ Volgograd State University, Volgograd, Russian Federation \\ Elena N. Nesmeyanova \\ Volgograd State University, Volgograd, Russian Federation \\ Margarita V. Postnova \\ Volgograd State University, Volgograd, Russian Federation
}

\begin{abstract}
Annotation. Three-dimensional (3D) bioprintingis a well-known promising technology for the production of artificial biological organs providing unprecedented versatility for manipulating cells and other biomaterials with precise control of their location in space. Over the past decade, a number of 3D bioprinting technologies have been developed. Unlike traditional manufacturing technologies, $3 \mathrm{D}$ bioprinting allows to produce individual or personalized fabric designs. This helps to deposit cells of the desired type with selected biomaterials and desired biologically active substances. Natural polymers play a leading role in maintaining cellular and biomolecular processes before, during, as well as after three-dimensional bioprinting. Polymers of biological origin can be extracted from natural raw materials by means of physical or chemical methods. These polymers are widely used as effective hydrogels for loading cells to form tissues, build a vascular, nervous, lymphatic network, and also to implement multiple biological, biochemical, 2 physiological, biomedical and other functions. Any natural polymers that have a sol-gel phase transition (i.e., a gel ㄱ. point) under certain conditions can be printed using the automatic layer-by-layer deposition method. In fact, very few $\oplus$ of them can be printed under various conditions (low temperature, without the help of physical, chemical, biochemical $\sum$ crosslinking of the incorporated polymer chains). Thus, not all natural polymers can meet all the basic requirements for ID $3 \mathrm{D}$ bioprinting. As a rule, natural polymers as the main component of various inks, which contain cells suspended in a specific medium, must meet several basic requirements for successful 3D bioprinting of organs, as well as clinical applications. These include biocompatibility, that is, non-toxic or without apparent toxicity; biodegradability (unlike non-biodegradable polymers can be used as auxiliary structures); biostability with sufficiently high mechanical I. strength both at the time of processing and during operation; bioprinterness (workability). This review is devoted to If modern research in the field of natural polymers used to print biological artificial organs.
\end{abstract}

Key words: three-dimensional bioprinting, natural polymers, rapid prototyping (RP), organ production, implantable bio-artificial organs, regenerative medicine.

УДК 53.047

БББ 30в6

\section{ПРИРОДНЫЕ ПОЛИМЕРЫ ДЛЯ 3D-БИОПЕЧАТИ ОРГАНОВ}

\author{
Галина Алексеевна Срослова
}

Волгоградский государственный университет, г. Волгоград, Российская Федерация

Юлия Александровна Зимина

Волгоградский государственный университет, г. Волгоград, Российская Федерация 


\section{Елена Николаевна Несмеянова}

Волгоградский государственный университет, г. Волгоград, Российская Федерация

\section{Маргарита Викторовна Постнова}

Волгоградский государственный университет, г. Волгоград, Российская Федерация

Аннотация. Трехмерная (3D) биопечать, известная многообещающая технология для производства искусственных биологических органов, обеспечивающая беспрецедентную универсальность для манипулирования клетками и другими биоматериалами с точным контролем их местоположения в пространстве. За последнее десятилетие был разработан ряд технологий 3D-биопечати. В отличие от традиционных технологий изготовления, 3D-биопечать позволяет изготавливать индивидуальные или персонализированные тканевые конструкции. Это помогает депонировать клетки желаемого типа с выбранными биоматериалами и желаемыми биологически активными веществами. Природные полимеры играют ведущую роль в поддержании клеточных и биомолекулярных процессов как до, во время, так и после трехмерной биопечати. Полимеры биологического происхождения могут быть извлечены выделены из природного сырья с использованием физических или химических методов. Эти полимеры широко используются в качестве эффективных гидрогелей для загрузки клеток для формирования тканей, построения сосудистой, нервной, лимфатической сети, а также для реализации множественных биологических, биохимических, физиологических, биомедицинских и других функций. Любые природные полимеры, которые имеют золь-гель фазовый переход (то есть точку гелеобразования) при определенных условиях, могут быть напечатаны с помощью автоматического послойного способа осаждения. Фактически же, очень немногие из них могут быть напечатаны при различных условиях (низкая температура, без помощи физического, химического, биохимического сшивания включенных полимерных цепей). Таким образом, не все природные полимеры могут соответствовать всем основным требованиям для 3D-биопечати. Как правило, природные полимеры как основной компонент различных чернил, которые содержат клетки, взвешенные в определенной среде, должны отвечать нескольким основным требованиям для успешной 3D-биопечати органов, а также клинических применений. К ним относятся биосовместимость, то есть нетоксичные или без явной токсичности; биоразлагаемость (в отличие от небиоразлагаемых полимеров можно использовать в качестве вспомогательных структур); биостабильность с достаточно высокой механической прочностью как на момент обработки, так и в процессе эксплуатации; биопринтерность (обрабатываемость). Данный обзор посвящен современным исследованиям в области природных полимеров, используемых для печати биологических искусственных органов.

Ключевые слова: трехмерная биопечать, природные полимеры, быстрое прототипирование (RP), производство органов, имплантируемые биоискусственные органы, регенеративная медицина.

Введение. Орган представляет собой совокупность тканей с определенными физиологическими функциями. В соответствии с современной классификацией организм человека состоит из примерно 80 органов [48; 49]. В настоящее время единственной эффективной терапией деформации, отказа органа является трансплантация аллотрансплантата. Однако, острая нехватка донорских органов, длительное лечение иммунодепрессантами, побочные эффекты иммунных осложнений в течение всей жизни и чрезвычайно высокая стоимость донорских органов значительно ограничивают его клиническое применение [3].

Существует растущая потребность в производстве биоискусственных органов для замены либо восстановления поврежденных, деформированных органов. Эта потребность огромна для всех типов органов, особенно для внутренних, таких как - печень, сердце, почки, легкие и желудок, связанных с хроническими и острыми поражениями [27; 35]. Типичным примером является то, что в США для восстановления пораженных органов требуется участие доноров (примерно одна десятая доноров для проведения 34 миллионов хирургических процедур) [38]. Только в 2013 году в трансплантации органов нуждалось более 117 тыс. пациентов, при этом для них было доступно только 28 тысяч подходящих органов [22].

Серьезный дефицит донорских органов наряду с побочными эффектами отторжения аллотрансплантата и чрезвычайно высокой стоимостью привела к появлению многочисленных стратегий производства органов за последние несколько десятилетий $[15 ; 20 ; 21$; $25 ; 39 ; 45 ; 47]$. Основные научные исследова- 
ния в данной области сконцентрированы на разработке эффективных технологий биопечати и поиске биосовместимых материалов с заданными свойствами.

Трехмерная биопечать с использованием природных полимеров как перспективная технология в регенеративной медицине. В последнее время трехмерная (3D) биопечать, также называемая технологией быстрого прототипирования (RP), или аддитивного производства (AM) и производства твердых форм (SFM), стала перспективным способом производства искусственных органов с помощью автоматического послойного двухслойного метода осаждения $[6 ; 17 ; 40]$. Наиболее важной характеристикой технологий трехмерной биопечати является печать живых клеток вместе с полимерными гидрогелями и/или другими биологически активными веществами в качестве «имплантов». Различные типы клеток могут быть заключены в полимерные гидрогели.

Полимерные гидрогели представляют собой трехмерные гидрофильные сети, которые могут поглощать и удерживать большое количество воды при определенных физических, биохимических, физиологических условиях. Полимерные гидрогели, которые использовались как материал для трехмерной биопечати ткани или органа, представляют собой как натуральные, так и синтетические полимеры, а также их комбинации [19; 26; 44].

За последнее десятилетие природные полимеры в качестве основных компонентов 3D-печатных «имплантов» сыграли решающую роль в различных технологиях 3D-биопечати. Поведение клеток в природных полимерных гидрогелях можно контролировать путем изменения физических, химических, биохимических, физиологических свойств используемых полимеров. При разработке новых технологий авторы преодолели ряд проблем, которые препятствовали прогрессу в данной области, а именно, крупномасштабная инженерия тканей органов, сохранение живой ткани (или органа), построение сложных сосудистых и нейронных сетей, производство сложных искусственных органов, частично или полностью контролируемое вовлечение (или дифференцировка) стволовых клеток [39-47].
Природные полимеры (биополимеры) могут быть получены из природного сырья с помощью различных методов. Примерами природных полимеров являются шелк, шерсть, дезоксирибонуклеиновая кислота (ДНК), целлюлоза, белки. Эти полимеры широко применяются во многих областях промышленности, таких как пищевая, текстильная, целлюлозно-бумажная, деревообрабатывающая, фармацевтическая и т. д.

Некоторые природные полимеры, такие как желатин, альгинат, фибриноген, гиалуроновая кислота, являются водорастворимыми. Это означает, что эти полимеры могут растворяться в жидкостях, подходящих для жизнедеятельности клеток, таких как среда для культивирования клеток или забуференный фосфатом физиологический раствор, с образованием растворов (гидрогелей). Теоретически любые биополимеры, которые имеют зольгель- фазовый переход (то есть точку гелеобразования) при определенных условиях, могут использоваться в 3D-печати в технологии автоматического послойного метода осаждения. Фактически же очень немногие из них могут быть применены при благоприятных условиях для клетки (например, при комнатной температуре) без помощи дополнительных методов физического, химического, биохимического сшивания включенных полимерных цепей. В целом очень немногие природные полимеры могут отвечать всем основным требованиям для 3D-биопечати [5; 24; 46].

Каждый полимер обладает своими особыми физико-химическими характеристиками, прежде всего, устойчивостью к изменению таких факторов как, температура, свет, $\mathrm{pH}$, природой взаимодействия с клеточным материалом. Исследование возможности применения тех или иных биополимеров в качестве материалов для 3D-печати с учетом их особенностей и свойств имеет огромное научное значение и может принести коммерческую прибыль в различных областях биомедицины.

\section{Природные полимеры для биопечати}

Альгинат. Альгинат, представляет собой анионный полисахарид, полученный из бурых водорослей. Термин «альгинат» обыч- 
но используется для солей альгиновой кислоты, которая состоит из $\beta$-D-маннуроновой кислоты (блок M) и $\alpha$-L-глюкуроновой кислоты (блок $\mathrm{G}$ ) и может относиться ко всем производным альгиновой кислоты и самой альгиновой кислоте [31]. Альгинат может растворяться в воде и химически сшиваться двухвалентными катионами, такими как ионы кальция $\left(\mathrm{Ca}^{2+}\right)$, стронция $\left(\mathrm{Sr}^{2+}\right)$ и бария $\left(\mathrm{Ba}^{2+}\right)$, что особенно важно для процессов заживления ран и регенерации тканей $[9 ; 18 ; 34]$. Соотношение между блоком $\mathrm{M}$ и $\mathrm{G}$ тесно связано с физико-химическими свойствами раствора альгината и образующегося геля. Более высокое отношение G/M обеспечивает жесткость полимерной структуры и более высокие механические свойства, в то время как более низкое отношение $\mathrm{G} / \mathrm{M}$ увеличивает гибкость [11;33].

Альгинатные и композитные альгинатные гидрогели используются в некоторых технологиях трехмерной биопечати из-за их хорошей биосовместимости (низкой токсичности, неиммуногенности) и способности к гелеобразованию [4]. Трехмерная биопечать с применением альгинатов может быть осуществлена на основе различных механизмов, таких как биоплотирование гидрогеля в клетках в среде для печати, осаждение сшитых полимеров с помощью соаксиального сопла. Каждая из этих технологий 3D-биопечати имеет свои плюсы и минусы.

Впервые технология 3D-биопечати с применением альгината натрия с гидрогелем желатина в качестве добавки была осуществлена профессором Х. Вангом в 2003 г. [36]. Низкая температура золь-гель-перехода раствора альгината (ниже $0{ }^{\circ} \mathrm{C}$ ) обусловливает необходимость применения добавок, повышающих температуру гелеобразования. Поэтому альгинат применяют в сочетании с желатином, температура гелеобразования которого $28{ }^{\circ} \mathrm{C}$ [37]. Процесс гелеобразования интенсифицируют также с помощью методов физического и химического сшивания.

При биопечати вязкость насыщенного клетками альгинатного гидрогеля в значительной степени зависит от концентрации полимеpa, молекулярной массы, фенотипа и плотности клеток. При применении химического сшивания, когда клетки погружены в альгинатный гидрогель с высокой концентрацией полимеpa, их биологическая активность сильно ограничивается. Более низкая концентрация альгинатного гидрогеля обеспечивает более высокую жизнеспособность клеток и способность к пролиферации.

Гиалуроновая кислота. Гиалуроновая кислота (далее - ГК), или гиалуронан - это полисахарид, содержащийся в живых организмах, состоящий из D-глюкуроновой кислоты и $\mathrm{N}$-ацетил-D-глюкозамина [32]. Как компонент гетерогенной внеклеточной матрицы (ЕСM), ГК обладает превосходной биосовместимостью и способностью к биоразложению, что играет существенную роль в пролиферации клеток, ангиогенезе и взаимодействиях клеток с рецепторами. ГК может быстро разлагаться (по гликолитическому пути) гиалуронидазой, $\beta$-глюкуронидазой и $\beta-\mathrm{N}$-ацетилглюкозаминидазой до олигосахаридов с низкой молекулярной массой [30]. ГК - гидрофильный полимер, который может образовывать высоковязкие гидрогели при низких концентрациях и может применяться в качестве присадки для изменения вязкости гелей на основе желатина.

Как и большинство природных полимеров, ГК обладает плохими механическими свойствами, что приводит к низкой точности формы при трехмерной биопечати. Были разработаны многочисленные модификации для улучшения механических свойств и точности формы при процессах 3D-печати на основе ГК. Эти модификации включают физическое или химическое сшивание ГК с другими полимерами. Например, метакрилат гиалуроновой кислоты (МГК) представляет собой природно-синтетический гибридный полимер, образующийся путем фотохимического сшивания ГК и метакрилата [2]. Следует подчеркнуть, что, хотя МГК обладает улучшенными физическими свойствами, низкая биоразлагаемость МГК сильно ограничивает его применение в области биопечати органов [7].

Коллаген. В последнее время природный коллаген стал широко использоваться в качестве каркасного материала для тканевой инженерии. Он может значительно улучшить адгезию, пролиферацию и дифференцировку остеобластов, хондробластов и мезенхимальных стволовых клеток на пористых каркасах 
[23]. Размер пор 50-150 мкм коллагенового каркаса облегчает засев клеток на поверхности пор. Предполагается, что молекула коллагена, которая имеет те же пептидные домены RGD, что и желатин, может распознаваться рецепторами интегрина на клеточной мембране и способствовать клеточной адгезии и пролиферации. Тем не менее свойство коллагена растворяться в кислотной среде может быть препятствием для широкого применения его в 3D-печати.

Коллаген типа I и II часто использовался для 3D-печати на каркасах для восстановления хрящей и костей. Существует три очевидных преимущества использования 3Dпечатных «строительных лесов» для восстановления тканей. Во-первых, большинство 3D-печатных каркасов имеют увеличенные проходные каналы, которые отличаются от традиционных пористых каркасов для тканевой инженерии и способствуют транспортировке питательных веществ, кислорода и метаболитов. Во-вторых, структурная морфология и композиционный материал 3D-печатных каркасов могут быть градиентными, что является преимуществом для реализации множества функциональных возможностей. B-третьих, живые клетки могут быть непосредственно включены в биосовместимые материалы для конструирования твердых или мягких тканей и органов.

До настоящего времени низкая вязкость и быстрая скорость разложения гидрогелей из чистого коллагена серьезно ограничивали их применение в трехмерной биопечати ткани / органа.

Фибрин. Фибрин - это волокнистый, не глобулярный белок, полученный из крови, образующийся при полимеризации фибриногена в присутствии протеазы тромбина [16]. За последние несколько десятилетий фибрин широко использовался во многих биомедицинских областях. По сравнению с природными полимерами растительного происхождения, такими как альгинат и агароза, фибрин обладает более высокой биосовместимостью. В контексте жизнеспособности клеток гидрогель фибрина обладает суперцитосовместимостью в плане инкапсуляции, доставки и культивирования клеток [41-43]. Что касается скорости разложения, то фибрин может быстро разла- гаться из-за присутствия протеолитических ферментов [14].

Несмотря на превосходные биологические, биомедицинские свойства, низкую вязкость, растворы фибрина обладают избыточно высокой скоростью гелеобразования, скоростью разложения и ограниченную механическую прочность. При слишком высокой скорости гелеобразования трудно контролировать процесс образования стабильных трехмерных структур. Эффективным решением является смешивание раствора фибриногена с другими химически сшиваемыми природными полимерами, такими как желатин, альгинат, гиалуронан и коллаген.

Как и альгинат, впервые фибрин был использован в трехмерной биопечати профессором Х. Вангом в 2007 году. В данной технологии фибриноген использовался как добавка к гидрогелю на основе желатина для производства печеночной или васкуляризованной печеночной ткани [46]. Физическое смешивание и химическое сшивание фибриногена с молекулами желатина может, очевидно, препятствовать разрушению 3D-печатных конструкций, замедлить скорость разложения полимера и улучшить структурную стабильность.

Хитозан. Хитозан - это природный полисахарид (полученный из раковины креветок), образующийся при деацетилировании хитина, который применяется во многих биомедицинских областях, таких как восстановление костей, кожи и хрящей, из-за его низких или нетоксичных, антибиотических и биоразлагаемых свойств $[1 ; 10]$. Хитозан может разлагаться лизоцимами [10]. Низкая механическая прочность и свойства медленного гелеобразования растворов хитозана, очевидно, затрудняют его применение в областях 3D-печати органов.

Агароза. Агароза, полученная из клеточной стенки красных водорослей, представляет собой природный линейный полисахарид, который в основном состоит из $\beta$-D-галактопиранозы и 3,6-ангидро- $\alpha$-L-галактопиранозы [13]. Это еще один природный полимер с тепловым откликом, помимо желатина, с температурой сжижения приблизительно $30{ }^{\circ} \mathrm{C}$, который подходит для экструзионных процессов 3D-биопечати [28].

Децеллюляризованный внеклеточный матрикс (dECM). Децеллюляризован- 
ный внеклеточный матрикс представляет собой смесь природных полимеров, которая получается путем децеллюляризации различных тканей животных, таких как кожа, подслизистая оболочка тонкого кишечника и печень [8]. После децеллюляризации состав и топология исходных тканей могут быть в значительной степени сохранены, что может обеспечить тканеспецифичную микросреду для сохранения клеточно-специфических функций. Процессы децеллюляризации могут быть физическими, химическими, биохимическими (например, ферментативными) или их комбинациями, которые могут влиять на конечные составы dECM [12]. Полученные растворы на основе dECM превращаются в гель сразу после достижения $15^{\circ} \mathrm{C}$ и образуют физически сшитые гидрогели. Сообщалось, что полученный из печени dECM может быть использован в качестве функционального субстрата для культуры гепатоцитов. Специфичный для печени dECM может поддерживать функции гепатоцитов посредством секреции альбумина, экспрессии мРНК, насоса для экспорта желчной соли (BSEP) и ко-транспортера натрий-желчных кислот (NTCP), и может рассматриваться как перспективный материал для каркаса в 3D-биопечати тканей [29].

При трехмерной биопечати органов $\mathrm{dECM} \mathrm{способен} \mathrm{создавать} \mathrm{клеткам} \mathrm{благопри-}$ ятную среду. Но из-за низкой вязкости $\mathrm{dECM}$ часто требуется совместное применение других полимеров, чтобы обеспечить базовую 3D-печать и точность формы [46].

Заключение. Производство органов это междисциплинарная область, в которой необходимо объединить широкий спектр наук, таких как биология, материаловедение, химия, физика, механика, информатика и медицина, для проектирования и создания биоискусственных органов с необходимыми типами клеток, сосудистыми, нейронными, лимфатическими сетями, гетерогенной внеклеточной матрицей и ожидаемыми биологическими, биохимическими, физиологическими функции.

Несмотря на все достижения в данной области, проблемы все еще остаются. Наиболее перспективные направления исследований связаны с поиском новых полимеров с высокой биосовместимостью, способностью работать в физиологических условиях среды и улучшенными физико-химическими свойствами. Для решения этих задач могут быть исследованы различные комбинации природных и синтетических полимеров, а также использованы возможности модификации с применением различных методов сшивания полимерных нитей. Таким образом, возможности 3D-печати позволят сделать достижения регенеративной медицины более доступными.

\section{СПИСОК ЛИТЕРАТУРЫ}

1. Зимина, Ю. А. Применение биопрепаратов на основе хитозана в сельском хозяйстве / Ю. А. Зимина, Г. А. Срослова, М. В. Постнова // Природные системы и ресурсы. - 2018. - Т. 3, № 3. - С. 22-28.

2. A Synthetic Thermosensitive Hydrogel for Cartilage Bioprinting and Its Biofunctionalization with Polysaccharides / A. A. Abbadessa [et al.] // Biomacromolecules. - 2016. - Vol. 17, № 6. - P. 21372147. DOI: https//doi.org/10.1021/acs.biomac.6b00366.

3. Axpe, E. Applications of Alginate-Based Bioinks in 3D bioprinting / E. Axpe, M.L. Oyen // Int. J. Mol. Sci. - 2016. - Vol. 17, № 12. - P. 1976. DOI: https/ /doi.org/10.3390/ijms17121976.

4. A Review of Trends and Limitations in Hydrogel-Rapid Prototyping for Tissue Engineering / T. Billiet [et al.] // Biomaterials. - 2015. -Vol. 33, № 26. - P. 6020-6041. DOI: https//doi.org/10.1016/ j.biomaterials.2012.04.050.

5. Bioprinting Cellularized Constructs Using a Tissue-Specific Hydrogel Bioink / A. Skardal [et al.] // J. Vis. Exp. -2016. - Vol. 110. -P. 53606. DOI: https// doi.org/10.3791/53606.

6. Characterization of a PLGA Sandwiched Cell / Fibrin Tubular Construct and Induction of the Adipose Derived Stem Cells into Smooth Muscle Cells // X. Wang [et al.] // Mater. Sci. Eng. - 2011. - Vol. 31. - P. 801-808. DOI: https//doi.org/10.1016/j.msec.2010.10.007.

7. Direct Construction of a Three-Dimensional Structure with Cells and Hydrogel / Y. Yan [et al.] // J. Bioact. Compat. Polym. - 2005. - Vol. 20, № 3.P. 259-269. DOI:https//doi.org/10.1016/j. ejca.2010.10.025.

8. Drury, J. L. The Tensile Properties of Alginate Hydrogels / J. L. Drury, R. G. Dennis, D. J. Mooney// Biomaterials. - 2004. - Vol. 25, № 16. P. 3187-3199. DOI: https//doi.org/10.1016/j.biomaterials. 2003.10.002.

9. 3D Cell Printed Tissue Analogues: A New Platform for Theranostics / Y.-J. Choi [et al.] // Theranostics. - 2017. - Vol. 7, № 12. - P. 3118-3137. DOI: https//doi.org/10.1007/s10439-016-1612-8.

10. 2D, 3D and 4D Active Compound Delivery in Tissue Engineering and Regenerative Medicine / 
N. Hanauer [et al.]//Curr. Pharm. Des. -2015. - Vol. 21, № 12. - P. 1506-1516. DOI: https//doi.org/10.2174/ 1381612821666150115153417.

11. Effects of Diabetes and Hypoxia on Gene Markers of Angiogenesis (HGF, cMET, uPA and uPAR, TGF-б, TGF-в, bFGF and Vimentin) in Cultured and Transplanted Rat Islets / B. Vasir [et al.] // Diabetologia. 2000. - Vol. 43, № 6. - P. 763-768. DOI: https//doi.org/ 10.1007/s001250051374.

12. Fu, X. T. Agarase: Review of Major Sources, Categories, Purification Method, Enzyme Characteristics and Applications / X. T. Fu, S. M. Kim // Mar. Drugs. 2010. - Vol. 8, № 1. - P. 200-218. DOI: https//doi.org/ 10.3390/md8010200.

13. Global Surveillance of Cancer Survival 19952009: Analysis of Individual Data for 25,676,887 Patients from 279 Population-Based Registries in 67 Countries (CONCORD-2) / C. Allemani [et al.] // Lancet. -2015. Vol. 385. - P. 977-1010. DOI: https//doi.org/10.1016/ S0140-6736(14) 62038-9.

14. Gasperini, L. Natural Polymers for the Microencapsulation of Cells / L. Gasperini, J. F. Mano, R. L. Reis// J. R. Soc. Interface. - 2014. - Vol. 11, № 100.P. 2014-2017. DOI: https//doi.org/10.1098/rsif.2014.0817.

15. In Vitro Angiogenesis of 3D Tissue Engineered Adipose Tissue / R. Yao [et al.] // Bioact. Compat. Polym. - 2009. - Vol. 24. - № 1.- P. 5-24. DOI: https//doi.org/10.1177/ 0883911508099367.

16. Langer, R. Tissue Engineering / R. Langer, J.P. Vacanti // Science. -1993. - Vol. 260. - P. 920-926. DOI: https//doi.org/10.1126/science.8493529.

17. Lei, M. Biodegradable Polymers and Stem Cells for Bioprinting / M. Lei, X. Wang // Molecules. 2016. - Vol. 21, № 5. - P. 539. DOI: https//doi.org/ $10.3390 /$ molecules21050539.

18. Lee, K. Y. Alginate: Properties and Biomedical Applications / K. Y. Lee, D. J. Mooney // Prog. Polym. Sci. - 2012. - Vol. 37, № 1. - P. 106-126. DOI: https// doi.org/10.1016/ j.progpolymsci.2011.06.003.

19. Mao, A.S. Regenerative Medicine: Current Therapies and Future Directions / A. S. Mao, D. J. Mooney // Proc. Natl. Acad. Sci. USA. - 2015. Vol. 112, № 47. - P. 14452-14459. DOI: https//doi.org/ 10.1073 / pnas. 1508520112 .

20. Moniaux, N. A Reengineered Liver for Transplantation / N. Moniaux, J.A. Faivre// J. Hepatol. 2011. - Vol.54, № 2. - P. 386-387. DOI: https//doi.org/ $10.1016 /$ j. jhep.2010.07.053.

21. Mosesson, M. W. Fibrinogen and Fibrin Structure and Functions / M. W. Mosesson // J. Thromb. Haemost. - 2005. - Vol. 3, № 8. - P. 1894-1904. DOI: https//doi.org/10.1111/j.1538-7836.2005.01365.x.

22. Nagel, T. The Composition of Engineered Cartilage at the Time of Implantation Determines the Likelihood of Regenerating Tissue with a Normal Collagen Architecture / T. Nagel, D. Kelly // J. Tissue
Eng. Part A. - 2013. - Vol.19, № 7. - P. 824-833. DOI: https//doi.org/10.1089/ten.TEA.

23. Nair, L.S. Biodegradable Polymers as Biomaterials / L.S. Nair, C.T. Laurencin // Prog. Polym. Sci. -2007. - Vol. 6, № 9. - P. 762-798. DOI: https// doi.org/10.1163/156856295x00175.

24. Ozbolat, I. T. Current Advances and Future Perspectives in Extrusion-Based Bioprinting / I.T. Ozbolat, M. Hospodiuk // Biomaterials. - 2016. Vol. 76. - P. 321-343. DOI: https//doi.org/10.1016/ j.biomaterials.2015.

25. Panwar, A. Current Status of Bioinks for Micro-Extrusion-Based 3D Bioprinting / A. Panwar, L.P. Tan // Molecules. - 2016. - Vol. 21, № 6. - P. 685. DOI: https//doi.org/10.3390/molecules21060685.

26. Park, Y. D. Photopolymerized Hyaluronic Acid-Based Hydrogels and Interpenetrating Networks / Y. D. Park, N. Tirelli, J. A. Hubbell // Biomaterials. 2003. - Vol. 24, № 6. - P. 893-900. DOI: https//doi.org/ 10.1016/s0142-9612(02)00420-9.

27. Patrick, C. W. Jr. Adipose Tissue Engineering: The Future of Breast and Soft Tissue Reconstruction Following Tumor Resection / C.W. Jr. Patrick // Semin. Surg. Oncol. - 2000. - Vol. 19, № 3. - P. 302-311. DOI: https//doi.org/10.1002/1098-2388(200010/11)19:3s.

28. Pawar, S. N. Alginate Derivatization: A Review of Chemistry, Properties and Applications / S. N. Pawar, K. J. Edgar // Biomaterials. - 2012. - Vol. 33. - № 11. P. 3279-3305. DOI: https//doi.org/10.1016/ j.biomaterials.2012.01.007.

29. Perfusion-Decellularized Matrix: Using Nature's Platform to Engineer a Bioartificial Heart / H.C. Ott [et al.] // Nat. Med. - 2008. - Vol. 14, № 2. P. 213-221. DOI: https//doi.org/10.1038/nm1684.

30. Preparation and Characterization of a Collagen / Chitosan / Heparin Matrix for an Implantable Bioartificial Liver / X. Wang [et al.] // J. Biomater. Sci. Polym. Ed. - 2005. - Vol.16, № 9. - P. 1063-1080. DOI: https//doi.org/10.1163/1568562054798554.

31. Preparation and Rheological Characterization of a Gel form of the Porcine Urinary Bladder Matrix / D. O. Freytes [et al.] // Biomaterials. - 2008. - Vol. 29, № 11. - P. 1630-1637. DOI: https//doi.org/10.1016/ j.biomaterials.2007.12.014.

32. Printing Three-Dimensional Tissue Analogues with Decellularized Extracellular Matrix Bioink / F. Pati [et al.] // Nat. Commun. -2014. - Vol. 6, № 3. - P. 3935. DOI: https//doi.org/10.1038/ ncomms4935.

33. Process Development of an Acellular Dermal Matrix (ADM) for Biomedical Applications / R. N. Chen [et al.] // Biomaterials. - 2004. - Vol. 25. - P. 2679-2686. DOI: https//doi.org/10.1016/j.biomaterials.2003.09.070.

34. Progress in Organ 3D Bioprinting / F. Liu [et al.] // Int. J. Bioprint. - 2018. - Vol. 4. - P. 1-15. DOI: https//doi.org/10.18063/ijb.v4i1.128. 
35. Rapid Prototyping a New PolyurethaneCollagen Conduit and its Schwann Cell Compatibility / T. Cui [et al.]// Bioact. Compat. Polym. -2009. - Vol. 15, № 1. - P. 5-17. DOI: https//doi.org/10.1089/ten.tec.

36. Recellularization of Well-Preserved Acellular Kidney Scaffold Using Embryonic Stem Cells / B. Bonandrini [et al.] // Tissue Eng. Part A. 2014. - Vol. 20, № 9. - P. 1486. DOI: https//doi.org/ 10.1089/ten.TEA.2013.0269.

37. Stanton, M. M. Bioprinting of 3D Hydrogels / M. M. Stanton, J. Samitier, S. Sanchez // Lab Chip.2015. - Vol. 15, № 15. - P. 3111-3115. DOI: https// doi.org/10.1039/c5lc90069g.

38. Synthesis and Characterization of Hybrid Hyaluronic Acid-Gelatin Hydrogels / G. Camci-Unal [et al.] // Biomacromolecules. - 2013. - Vol. 14, № 4. P. 1085-1092. DOI: https//doi.org/10.1021/bm3019856.

39. The Integrations of Biomaterials and Rapid Prototyping Techniques for Intelligent Manufacturing of Complex Organs / X. Wang [et al.] // Advances in Biomaterials Science and Applications in Biomedicine. - Rijeka : In Tech, 2013. - P. 437-463. DOI: https// doi.org/10.5772/53114.

40. Tonnesen, H. H. Alginate in Drug Delivery Systems / H. H. Tonnesen, J. Karlsen // Drug Dev. Ind. Pharm. - 2002. - Vol. 28, № 6. - P. 621-630. DOI: https/ /doi.org/10.1081/ddc-120003853.

41. Wang, X. Intelligent Freeform Manufacturing ofComplex Organs // Artif. Org. - 2012. - Vol. 36, № 11.P. 951-961. DOI: https//doi.org/10.1111/j.15251594.2012.01499.x.

42. Wang, X. A Combined Rotational Mold for Manufacturing a Functional Liver System / X. A. Wang, Y. W. Huang, C. Liu // J. Bioact. Compat. Polym. -2015.Vol. 39, №4. -P. 436-451. DOI: https//doi.org/10.1177/ 0883911515578872

43. Wang, X. Optimizing the Step by Step Forming Processes for Fabricating a PLGA Sandwiched Cell / Hydrogel Construct / X. Wang, S. Sui, C. Liu // J. Appl. Polym. Sci. - 2011. - Vol. 120, № 2. - P. 11991207. DOI: https//doi.org/10.1002/app.33093.

44. Wang, X. Pulsatile Culture of a PLGA Sandwiched Cell / Hydrogel Construct Fabricated Using a Step by Step Mold / Extraction Method / X. Wang, S. Sui //Artif. Organs. -2011. - Vol. 35, № 6. - P. 645-655. DOI: https//doi.org/10.1111/j.1525-1594.2010.01137.x.

45. Wang, X. Gelatin-Based Hydrogels for Controlled Cell Assembly / X. Wang, Y. Yan, R. Zhang // Biomedical Applications of Hydrogels Handbook. N. Y. : Springer, 2010. - P. 269-284. DOI: https//doi.org/ 10.1007/978-1-4419-5919-5 14.

46. Wang, X. Rapid Prototyping as Tool for Manufacturing Bioartificial Livers / X. Wang, Y. Yan, R. Zhang// Trends Biotechnol. - 2007. - Vol. 25, № 11.P. 505-513. DOI: https//doi.org/10.1177 / 088391151557 8872.
47. Wang, X. Recent Trends and Challenges in Complex Organ Manufacturing / X. Wang, Y. Yan, R. Zhang // Tissue Eng. Part B. - 2010. - Vol. 16, № 2.P. 189-197. DOI: https//doi.org/10.1089/ ten.TEB.2009.0576.

48. Widmaier, E. P. The Mechanisms of Body Function / E. P. Widmaier, H. Raff, K. T. Strang // Vander's Human Physiology. - N. Y. : McGraw-Hill, 2012. - P. 250-291.

49. Yelin, E. The Burden of Musculoskeletal Diseases in the United States / E. Yelin, S. Weinstein, T. King // Semin. Arthritis Rheum. - 2016. - Vol. 46, № 3. - P. 259-260. DOI: https//doi.org/10.1016/ j.semarthrit.2016.07.013.

\section{REFERENCES}

1. Zimina Ju.A., Sroslova G.A., Postnova M.V. Primenenie biopreparatov na osnove hitozana $\mathrm{V}$ sel'skom hozjajstve [Application of Chitosan-Based Biologics in Agriculture]. Prirodnye sistemy i resursy [Natural systems and resources], 2018, vol. 3, no. 3, pp. 22-28.

2. Abbadessa A., Mouser V.H., Blokzijl M.M., et al. A Synthetic Thermosensitive Hydrogel for Cartilage Bioprinting and its Biofunctionalization with Polysaccharides. Biomacromolecules, 2016, vol. 17, no. 6, pp. 2137-2147. DOI: https//doi.org/10.1021/ acs.biomac.6b00366.

3. Axpe E., Oyen M.L. Applications of AlginateBased Bioinks in 3D Bioprinting. Int. J. Mol. Sci., 2016, vol. 17, no. 12, p. 1976. DOI: https//doi.org/10.3390/ ijms17121976.

4. Billiet T., Vandenhaute M., Schelfhout J., et al. A Review of Trends and Limitations in Hydrogel-Rapid Prototyping for Tissue Engineering. Biomaterial, 2015, vol. 33, no. 12, pp. 6020-6041. DOI: https//doi.org/ 10.1016/j.biomaterials.2012.04.050.

5. Skardal A., Devarasetty M., Kang H.W., et al. Bioprinting Cellularized Constructs Using a TissueSpecific Hydrogel Bioink. J. Vis. Exp., 2016, vol. 110, pp. 53606. DOI: https//doi.org/10.3791/53606.

6. Wang X., Mäkitie A.A., Paloheimo K.-S., et al. Characterization of a PLGA Sandwiched Cell / Fibrin Tubular Construct and Induction of the Adipose Derived Stem Cells into Smooth Muscle Cells. Mater. Sci. Eng., 2011, vol. 31, pp. 801-808. DOI: https// doi.org/10.1016/j.msec.2010.10.007.

7. Yan Y., Wang X., Xiong Z., et al. Direct Construction of a Three-Dimensional Structure with Cells and Hydrogel. J. Bioact. Compat. Polym., 2005, vol. 20, no. 3, pp. 259-269. DOI: https//doi.org/10.1016 /j. ejca.2010.10.025.

8. Drury J.L., Dennis R.G., Mooney D.J. The Tensile Properties of Alginate Hydrogels. 
Biomaterials, 2004, vol. 25, no. 16, pp. 3187-3199. DOI: https//doi.org/10.1016/j.biomaterials.2003.10.002.

9. Choi Y.-J., YIH.-G., Kim S.-W., ChoD.-W. 3DCell Printed Tissue Analogues: A New Platform for Theranostics. Theranostics, 2017, vol. 7, no. 12, pp. 31183137. DOI: https//doi.org/10.1007/s10439-016-1612-8.

10. Hanauer N., Latreille P.L., Alsharif S., et al. 2D, 3D and 4D Active Compound Delivery in Tissue Engineering and Regenerative Medicine. Curr. Pharm. Des., 2015, vol. 21, no. 12, pp. 1506-1516. DOI: https// doi.org/10.2174/1381612821666150115153417.

11. Vasir B., Reitz P., Xu G., et al. Effects of Diabetes and Hypoxia on Gene Markers of Angiogenesis (HGF, cMET, uPA and uPAR, TGF-б, TGF-в, bFGF and Vimentin) in Cultured and Transplanted Rat Islets. Diabetologia, 2000, vol. 43, no. 6, pp. 763-768. DOI: https//doi.org/10.1007/s001250051374.

12. Fu X.T., Kim S.M. Agarase: Review of Major Sources, Categories, Purification Method, Enzyme Characteristics and Applications. Mar. Drugs., 2010, vol. 8, no. 1, pp. 200-218. DOI: https//doi.org/10.3390/ md8010200.

13. Allemani C., Weir H.K., Carreira H., et al. Global Surveillance of Cancer Survival 1995-2009: Analysis of Individual Data for 25,676,887 Patients from 279 Population-Based Registries in 67 Countries (CONCORD-2). Lancet, 2015, vol. 385, pp. 977-1010. DOI: https//doi.org/10.1016/S0140-6736(14) 62038-9.

14. Gasperini L., Mano J.F., Reis R.L. Natural Polymers for the Microencapsulation of Cells. J. $R$. Soc. Interface, 2014, vol.11, no. 100, pp. 2014-2017. DOI: https//doi.org/10.1098/ rsif.2014.0817.

15. Yao R., Zhang R., Yan Y., Wang X. In Vitro Angiogenesis of 3D Tissue Engineered Adipose Tissue. Bioact. Compat. Polym., 2009, vol. 24, no. 1, pp. 5-24. DOI: https//doi.org/10.1177/ 0883911508099367.

16. Langer R., Vacanti J.P. Tissue Engineering. Science, 1993, vol. 260, pp. 920-926. DOI: https//doi.org/ 10.1126/science.8493529.

17. Lei M., Wang X. Biodegradable Polymers and Stem Cells for Bioprinting. Molecules, 2016, vol. 21, no. 5, pp. 539. DOI: https//doi.org/10.3390/ molecules21050539.

18. Lee K.Y., Mooney D.J. Alginate: Properties and Biomedical Applications. Prog. Polym. Sci., 2012, vol. 37, no. 1, pp. 106-126. DOI: https//doi.org/10.1016 /j.progpolymsci.2011.06.003.

19. Mao A.S., Mooney D.J. Regenerative Medicine: Current Therapies and Future Directions. Proc. Natl. Acad. Sci. USA, 2015, vol. 112, no. 47, pp. 14452-14459. DOI: https//doi.org/10.1073/ pnas. 1508520112 .

20. Moniaux N., Faivre J.A. Reengineered Liver for Transplantation. J. Hepatol., 2011, vol. 54, no. 2, pp. 386-387. DOI: https//doi.org/10.1016/j. jhep.2010.07.053.
21. Mosesson M.W. Fibrinogen and Fibrin Structure and Functions. J. Thromb. Haemost., 2005, vol. 3, no. 8, pp. 1894-1904. DOI: https//doi.org/10.1111/ j.1538-7836.2005.01365.x.

22. Nagel T., Kelly D.J. The Composition of Engineered Cartilage at the Time of Implantation Determines the Likelihood of Regenerating Tissue with a Normal Collagen Architecture. J. Tissue Eng. Part A, 2013, vol.19, no. 7, pp. 824-833. DOI: https// doi.org/10.1089/ten.TEA.

23. Nair L.S., Laurencin C.T. Biodegradable Polymers as Biomaterials. Prog. Polym. Sci., 2007, vol. 6, no. 9, pp. 762-798. DOI: https//doi.org/10.1163/ $156856295 \times 00175$.

24. Ozbolat I.T., Hospodiuk M. Current Advances and Future Perspectives in Extrusion-Based Bioprinting. Biomaterials, 2016, vol. 76, pp. 321-343. DOI: https//doi.org/10.1016/j.biomaterials. 2015 .

25. Panwar A., Tan L.P. Current Status of Bioinks for Micro-Extrusion-Based 3D Bioprinting. Molecules, 2016, vol. 21, no. 6, p. 685. DOI: https//doi.org/10.3390/ molecules21060685.

26. Park Y.D., Tirelli N., Hubbell J.A. Photopolymerized Hyaluronic Acid-Based Hydrogels and Interpenetrating Networks. Biomaterials, 2003, vol. 24, no. 6, pp. 893-900. DOI: https//doi.org/10.1016/ s0142-9612(02)00420-9.

27. Patrick C.W. Jr. Adipose Tissue Engineering: The Future of Breast and Soft Tissue Reconstruction Following Tumor Resection. Semin. Surg. Oncol., 2000, vol. 19, no. 3, pp. 302-311. DOI: https//doi.org/10.1002/ 1098-2388(200010/11)19:3s.

28. Pawar S.N., Edgar K.J. Alginate Derivatization: A Review of Chemistry, Properties and Applications. Biomaterials, 2012, vol. 33, no. 11, pp. 3279-3305. DOI: https//doi.org/10.1016/j.biomaterials.2012.01.007.

29. Ott H.C., Matthiesen T.S., Goh S.K., et al. Perfusion-Decellularized Matrix: Using Nature's Platform to Engineer a Bioartificial Heart. Nat. Med., 2008, vol. 14, no. 2, pp. 213-221. DOI: https//doi.org/ $10.1038 / \mathrm{nm} 1684$.

30. Wang X., Yan Y., Lin F., et al. Preparation and Characterization of a Collagen / Chitosan / Heparin Matrix for an Implantable Bioartificial Liver.J. Biomater. Sci. Polym. Ed., 2005, vol. 16, no. 9, pp. 1063-1080. DOI: https//doi.org/10.1163/1568562054798554.

31. Freytes D.O., Martin J., Velankar S.S., et al. Preparation and Rheological Characterization of a Gel form of the Porcine Urinary Bladder Matrix. Biomaterials, 2008, vol. 29, no. 11, pp. 1630-1637. DOI: https//doi.org/10.1016/j.biomaterials.2007.12.014.

32. Pati F., Jang J., Ha D.-H., et al. Printing ThreeDimensional Tissue Analogues with Decellularized Extracellular Matrix Bioink. Nat. Commun., 2014, vol. 6, no. 3, p. 3935. DOI: https//doi.org/10.1038/ ncomms 4935 . 
33. Chen R.N., Ho H.O., Tsai Y.T., Sheu M.T. Process Development of an Acellular Dermal Matrix (ADM) for Biomedical Applications. Biomaterials, 2004, vol. 25, pp. 2679-2686. DOI: https//doi.org/ 10.1016/j.biomaterials.2003.09.070.

34. Liu F., Liu C., Chen Q., et al. Progress in Organ 3D Bioprinting. Int. J. Bioprint., 2018, vol. 4, pp. 1-15. DOI: https//doi.org/10.18063/ijb.v4i1. 128.

35. Cui T., Wang X., Yan Y., Zhang R. Rapid Prototyping a New Polyurethane-Collagen Conduit and its Schwann Cell Compatibility. Bioact. Compat. Polym, 2009, vol. 15, no. 1, pp. 5-17. DOI: https// doi.org/10.1089/ten.tec.

36. Bonandrini B., Figliuzzi M., Papadimou E., et al. Recellularization of Well-Preserved Acellular Kidney Scaffold Using Embryonic Stem Cells. Tissue Eng. Part A, 2014, vol. 20, no. 9, pp. 1486. DOI: https/ /doi.org/10.1089/ten.TEA.2013.0269.

37. Stanton M.M., Samitier J., Sanchez S. Bioprinting of3D Hydrogels. Lab Chip., 2015, vol. 15, no. 15, pp. 31113115. DOI: https//doi.org/10.1039/c5lc90069g.

38. Camci-Unal G., Cuttica D., Annabi N., et al. Synthesis and Characterization of Hybrid Hyaluronic Acid-Gelatin Hydrogels. Biomacromolecules, 2013, vol. 14, no. 4, pp. 1085-1092. DOI: https//doi.org/ 10.1021/bm3019856.

39. Wang X., Tuomi J., Mäkitie A.A., et al. The Integrations of Biomaterials and Rapid Prototyping Techniques for Intelligent Manufacturing of Complex Organs. Advances in Biomaterials Science and Applications in Biomedicine. Rijeka, In Tech Publ., 2013, pp. 437-463. DOI: https//doi.org/10.5772/53114.

40. Tonnesen H. H., Karlsen J. Alginate in Drug Delivery Systems. Drug Dev. Ind. Pharm., 2002, vol. 28, no. 6, pp. 621-630. DOI: https//doi.org/10.1081/ddc120003853

41. Wang, X. Intelligent Freeform Manufacturing of Complex Organs. Artif. Org., 2012, vol. 36, no. 11, pp. 951-961. DOI: https//doi.org/10.1111/j.15251594.2012.01499.x.

42. Wang X., Mäkitie A.A., Paloheimo K.-S., et al. A Combined Rotational Mold for Manufacturing a Functional Liver System. J. Bioact. Compat. Polym., 2015, vol. 39, no. 4, pp. 436-451. DOI: https//doi.org/ $10.1177 / 0883911515578872$.

43. Wang X., Sui S., Liu C. Optimizing the Step by Step Forming Processes for Fabricating a PLGA Sandwiched Cell / Hydrogel Construct. J. Appl. Polym. Sci., 2011, vol. 120, no. 2, pp. 1199-1207. DOI: https// doi.org/10.1002/app.33093.

44. Wang X., Sui S. Pulsatile Culture of a PLGA Sandwiched Cell / Hydrogel Construct Fabricated Using a Step by Step Mold / Extraction Method. Artif. Organs., 2011, vol. 35, no. 6, pp. 645-655. DOI: https// doi.org/10.1111/j.1525-1594.2010.01137.x.

45. Wang X., Yan Y., Zhang R. Gelatin-Based Hydrogels for Controlled Cell Assembly. Biomedical Applications of Hydrogels Handbook. New York, Springer Publ., 2010, pp. 269-284. DOI: https//doi.org/ 10.1007/978-1-4419-5919-5_14.

46. Wang X., Yan Y., Zhang R. Rapid Prototyping as Tool for Manufacturing Bioartificial Livers. Trends Biotechnol., 2007, vol. 25, no. 11, pp. 505-513. DOI: https//doi.org/10.1177/ 0883911515578872.

47. Wang X., Yan Y., Zhang R. Recent Trends and Challenges in Complex Organ Manufacturing. Tissue Eng. Part B, 2010, vol. 16, no. 2, pp. 189-197. DOI: https//doi.org/10.1089/ten.TEB.2009.0576.

48. Widmaier E.P., Raff H., Strang K.T. The Mechanisms of Body Function. Vander's Human Physiology. New York, McGraw-Hill Publ., 2012, pp. 250-291.

49. Yelin E., Weinstein S., King T. The Burden of Musculoskeletal Diseases in the United States. Semin. Arthritis Rheum., 2016, vol. 46, no. 3, pp. 259-260. DOI: https//doi.org/10.1016/j.semarthrit.2016.07.013.

\section{Information About the Authors}

Galina A. Sroslova,Candidate of Sciences (Biology), Associate Professor, Department of Bioengineering and Bioinformatics, Volgograd State University, Prosp. Universitetsky, 100, 400062 Volgograd, Russian Federation, sroslova.galina@volsu.ru.

Yuliya A. Zimina,Candidate of Sciences (Chemistry), Associate Professor, Department of Bioengineering and Bioinformatics, Volgograd State University, Prosp. Universitetsky, 100, 400062 Volgograd, Russian Federation, ziminaua@mail.ru.

Elena N. Nesmeyanova, Student, Department of Bioengineering and Bioinformatics, Volgograd State University, Prosp. Universitetsky, 100, 400062 Volgograd, Russian Federation, nesmeyanovaelena97@yandex.ru.

Margarita V. Postnova, Doctor of Sciences (Biology), Head of the Department of Bioengineering and Bioinformatics, Volgograd State University, Prosp. Universitetsky, 100, 400062 Volgograd, Russian Federation, postnova@volsu.ru. 


\section{БИОЛОГИЯ И БИОТЕХНОЛОГИЯ}

\section{Информация об авторах}

Галина Алексеевна Срослова, кандидат биологических наук, доцент кафедры биоинженерии и биоинформатики, Волгоградский государственный университет, просп. Университетский, 100, 400062 г. Волгоград, Российская Федерация, sroslova.galina@volsu.ru.

Юлия Александровна Зимина, кандидат химических наук, доцент кафедры биоинженерии и биоинформатики, Волгоградский государственный университет, просп. Университетский, 100, 400062 г. Волгоград, Российская Федерация, ziminaua@mail.ru.

Елена Николаевна Несмеянова, ассистент кафедры биоинженерии и биоинформатики, Волгоградский государственный университет, просп. Университетский, 100400062 г. Волгоград, Российская Федерация, nesmeyanovaelena97@yandex.ru.

Маргарита Викторовна Постнова, доктор биологических наук, заведующий кафедрой биоинженерии и биоинформатики, Волгоградский государственный университет, просп. Университетский, 100, 400062 г. Волгоград, Российская Федерация, postnova@volsu.ru. 